\title{
Bilateral Locked Facets at Lower Lumbar Spine Without Facet Fracture: A Case Report
}

\author{
Sang-Hyuk Im¹, Ki-Yeol Lee', Ho-Jin Bong ${ }^{2}$, Young-Sup Park ${ }^{1}$, Jong-Tae Kim ${ }^{1}$ \\ ${ }^{I}$ Department of Neurosurgery, Incheon Saint Mary's Hospital, The Catholic University of Korea \\ ${ }^{2} B M$ Neurosurgery Clinics
}

Bilateral locked facets at L4-5 without facet fracture is a rarely known disease. We present a case of a 37-year-old male patient diagnosed as traumatic L4-5 bilateral facets dislocation without facet fracture. We carried out open reduction, epidural hematoma removal, posterior interbody fusion. After surgery, we attained rapid improvement of the neurologic deficits and competent stabilization.

Key Words: Lumbar spine $\cdot$ Facet dislocation $\cdot$ Locked facet $\cdot$ Bilateral

\section{INTRODUCTION}

Bilateral locked facets are relatively common traumatic injuries of the cervical spine, but they are extremely rare in the lumbar spine. This is attributable to lumbar vertebrae having larger vertebral bodies and firm paraspinal muscle supporting them. In locked facet syndrome of lumbar vertebrae, in contrary to cervical lesion, a tremendous external force is needed to occur and fracture of facet is a common finding. This article contains a case of L4-5 locked facet. Discussing the clinical features and injury mechanisms of the lumbar locked facet through reviewing several relevant literatures.

\section{CASE REPORT}

A 37-year-old male welder with lower back pain and weakness in both lower extremities after being held down by aniron plate weighing $2,000 \mathrm{~kg}$. Neurologic examination revealed numbness in his right posterolateral thigh dorsiflexion and strength of both ankles and bigtoes was decreased (grade IV).

Radiograph of the lumbar spine revealed anterior slippage of the $4^{\text {th }}$ lumbar vertebra (Fig. 1). A computed tomography (CT) scan found a bilateral L4-5 facet dislocation in which

- Received: April 30, 2012 - Revised: September 10, 2012

- Accepted: September 25, 2012

Corresponding Author: Jong-Tae Kim, MD

Department of Neurosurgery, Incheon St. Mary's Hospital, 56 Dongsu-ro,

Bupyung-Gu, Incheon 403-720, Korea

Tel: +82-32-280-5973, Fax: +82-32-280-5991

Email: kjtns@olmh.cuk.ac.kr the L4 inferior articular process was located to the anterior of the L5 superior articular process (Fig. 2, 3). On T2-weighted magnetic resonance (MR) imaging, a high signal epidural hematoma was found at the L2 to L5 level and L4-L5 disc was disrupted (Fig. 4).

We proceeded open reduction and stabilization in which during surgery, we found that the interspinous ligaments and ligament flavum were partially torn and the L4-5 facets were locked bilaterally at the same time. The epidural hematoma at the anterior epidural space compressing the dura matter was removed.

The dislocation was reduced by resecting the superior facet
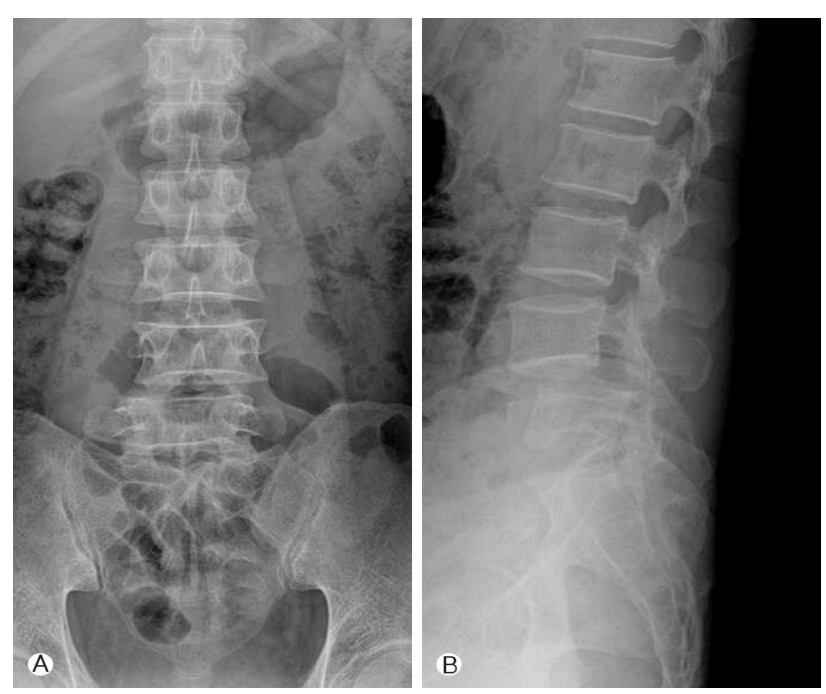

Fig. 1. (A) Anteroposterior lumbar radiograph shows lateral displacement of the L4 on L5. (B) Lateral lumbar radiograph shows bilateral locked facet at L4-5. 


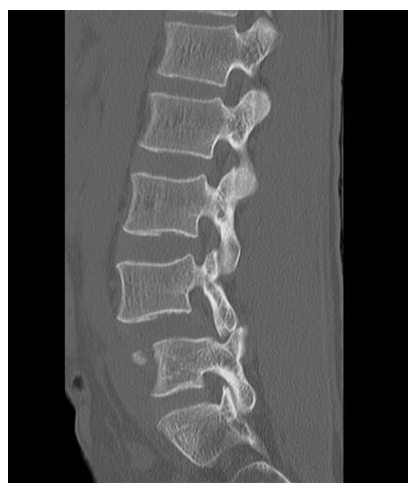

Fig. 2. Computed tomography (CT) scan reveals the L4-5 facet dislocation.

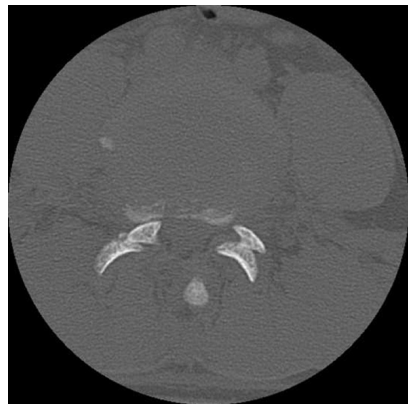

Fig. 3. Axial CT scan demonstrates the relationship between the inferior articular process of $\mathrm{L} 4$ and the superior articular process of L5.

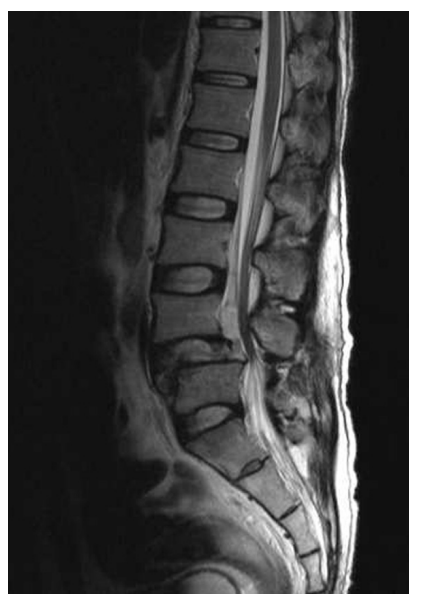

Fig. 4. Sagittal T2 weighted magnetic resonance (MR) imaging of the sagittal section shows a high signal epidural hematoma at $L 2$ to $L 5$ level and disrupteion of the intervertebral disc at L4-5.

of L5 and laminectomy of L4 was carried out. We then performed a posterior interbody fusion with cages, reinforced by a bilateral posterior rod and pedicle screw fixation. After surgery, rapid improvement of the neurologic deficits occurred. Six months later, he reported neither low back pain nor neurological deficit. Attached radiographs shows satisfactory alignment (Fig. 5).

\section{DISCUSSION}

Fracture-dislocations of the lumbosacral spine are rare. Bilaterally locked facet injuries without fracture are even less common with only 11 cases of literature ${ }^{1)}$. The majority of
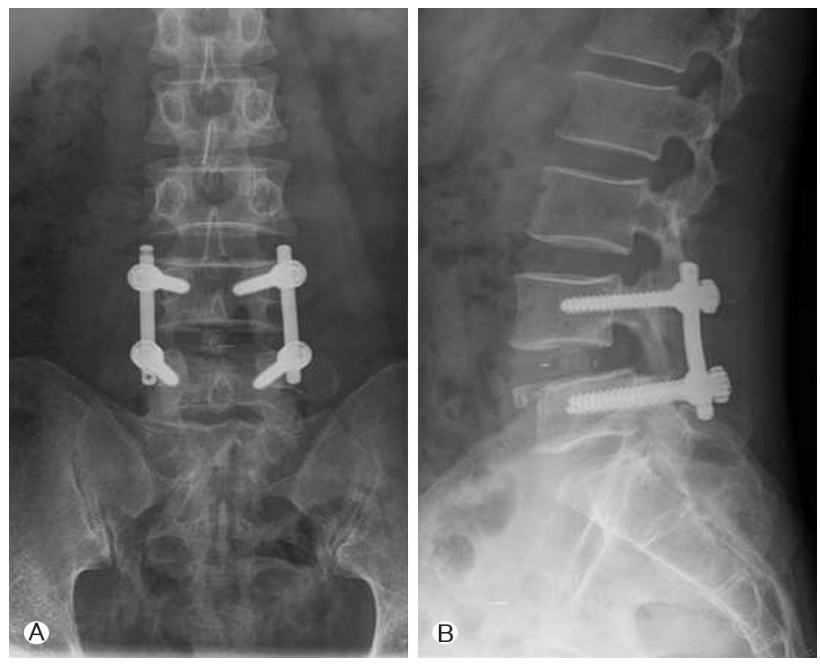

Fig. 5. (A), (B) Follow-up radiographs 6 months after surgery show satisfactory alignment.

dislocations involving the lumbar spine occur at the thoracolumbar junction, with decreasing frequency at the lower lumbar levels ${ }^{2,14}$. Anatomically, lumbar facet joints are arranged in the sagittal plane weak for hyperflexion yet strong for rotation. In 1940, Watson-Jones described one patient with a lumbosacral fracture-dislocation and considered the mechanism of injury to be forcible hyperextension ${ }^{10)}$. However, hyperflexion with varying degrees of distraction is the most frequent mechanism of facet dislocation in the lumbar spine ${ }^{4,5,7,8,10,15)}$. Hyperflexion alone is incapable of producing either pure dislocation or fracture-dislocation in the lumbar spine ${ }^{10)}$. Therefore, in this case, we consider the mechanism of injury was a combination of hyperflexion, distraction, and rotation.

Radiologic diagnosis of this injury is dependent on initial good quality radiographs, which will demonstrate the altered associated of lumbar facet joints ${ }^{14,16}$. But careful assessment of the CT and MRI studies demonstrated facet dislocation and disruption of soft tissues. The MRI allows assessment of the ligamentous and muscular structures, as well as the contents of the central canal and intervertebral neural foramen ${ }^{14)}$. A complete disruption of both joints in conjunction with avulsion of the interspinous ligaments and disc injury are expected to be highly unstable. CT examination proved to be extremely useful. The non-articular convex sides of the articular facets were shown to be in contact. Reconstruction in the sagittal plane can elegantly demonstrate the alignment of the vertebral bodies and facet joints and assess foraminal stenosis. In the coronal plane, lumbar spine alignment and asymmetry of the disc space can be assessed ${ }^{14)}$.

A previous study showed the lumbar facet orientation in a normal lumbar spine, and noted that the facet joint and laminae are more sagittally oriented at the L4-5 level, while at 
L5-S1 they are more frontally oriented ${ }^{8,17}$. In addition, a normal lumbar spine has the greatest flexion at L4-5 level ${ }^{8,10)}$. Taking these findings into consideration, facet dislocation may occur more easily at L4-5 than L5- S1, though the sacrum has good stability, it is fixed tightly to the pelvis by a sacro-iliac ligament.

Few authors have reported cases of bilateral dislocation successfully reduced with external reduction maneuvers ${ }^{3,6,9,19)}$. However, there is high risk of secondary neurological impairment. Therefore surgical treatment should be performed for all type of lumbosacral dislocation ${ }^{18)}$. The selection of anterior or posterior fusion may be chosen based upon the proficiency and experience of the surgeon as well as the instability of the injury ${ }^{13)}$. The presence of an anterior slip, even if moderate, indicates a severe disc injury. Disc assessment is mandatory in all cases because severe disc injuries requiring fusion may be found even in the absence of an anterior slip ${ }^{18)}$.

\section{REFERENCES}

1. Arnold PM, Malone DG, Han PP: Bilateral locked facets of the lumbosacral spine: treatment with open reduction and transpedicular fixation. J Spinal Cord Med 27(3):269-272, 2004

2. Bak KH, Cheong JH, Kim CH, Oh SH, Kim JM, Lee CB: Outcome of thoracolumbar fracture-dislocation according to the injury mechanism. Korean J spine 1:51-57, 2004

3. Boger DC, Chandler RW, Pearce JG, Balciunas A: Unilateral facet dislocation at the lumbosacral junction. Case report and literature review. J Bone Joint Surg Am 65(8):1174-1178, 1983

4. Das De S, McCreath SW: Lumbosacral fracture-dislocations. A report of four cases. J Bone Joint Surg Br 63-B(1):58-60, 1981

5. Denis F: The three column spine and its significance in the classification of acute thoracolumbar spinal injuries. Spine (Phila Pa 1976) 8(8):817-831, 1983

6. Hilibrand AS, Urquhart AG, Graziano GP, Hensinger RN: Acute spondylolytic spondylolisthesis. Risk of progression and neurological complications. J Bone Joint Surg Am 77(2):190-196, 1995
7. Levine AM, Bosse M, Edwards CC: Bilateral facet dislocations in the thoracolumbar spine. Spine (Phila Pa 1976) 13(6):630640, 1988

8. Mori K, Hukuda S, Katsuura A, Saruhashi Y, Asajima S: Traumatic bilateral locked facet at L4-5: report of a case associated with incorrect use of a three-point seatbelt. Eur Spine J 11(6): 602-605, 2002

9. Newell RL: Lumbosacral fracture-dislocation: a case managed conservatively, with return to heavy work. Injury 9(2):131-134, 1977

10. Roaf. R: A study of the mechanics of spinal injuries. J Bone Joint Surg Br 42-B(4):810-823, 1960

11. Watson-Jones R:Fractures and joint injuries, $1^{\text {st }}$ ed. Baltimore (MD): Williams \& Wilkins;1940

12. Reddy SJ, Al-Holou WN, Leveque JC, La Marca F, Park P: Traumatic lateral spondylolisthesis of the lumbar spine with a unilateral locked facet: description of an unusual injury, probable mechanism, and management. J Neurosurg Spine 9(6): 576-580, 2008

13. Song KJ, Lee KB: Bilateral facet dislocation on L4-L5 without neurologic deficit. J Spinal Disord Tech 18(5):462-464, 2005

14. Stuart RM, Song SJ: Unilateral lumbosacral facet joint dislocation without associated fracture. Australas Radiol 48(2):224-229, 2004

15. Taylor GA, Eggli KD: Lap-belt injuries of the lumbar spine in children: a pitfall in CT diagnosis. AJR Am J Roentgenol 150(6):1355-1358, 1988

16. Tsirikos AI, Saifuddin A, Noordeen MH, Tucker SK: Traumatic lumbosacral dislocation: report of two cases. Spine (Phila Pa 1976) 29(8):E164-168, 2004

17. Van Schaik JP, Verbiest H, Van Schaik FD: The orientation of laminae and facet joints in the lower lumbar spine. Spine (Phila Pa 1976) 10(1):59-63, 1985

18. Vialle R, Charosky S, Rillardon L, Levassor N, Court C: Traumatic dislocation of the lumbosacral junction diagnosis, anatomical classification and surgical strategy. Injury 38(2):169-181, 2007

19. Zoltan JD, Gilula LA, Murphy WA: Unilateral facet dislocation between the fifth lumbar and first sacral vertebrae. case report. J Bone Joint Surg Am 61(5):767-769, 1979 